\title{
Shelf Life Extension of Ricotta Cheese Using Coatings of Galactomannans from Nonconventional Sources Incorporating Nisin against Listeria monocytogenes
}

\author{
Joana T. Martins, Miguel A. Cerqueira, Bartolomeu W. S. Souza, \\ Maria do Carmo Avides, and António A. Vicente* \\ IBB-Institute for Biotechnology and Bioengineering, Centre of Biological Engineering, \\ Universidade do Minho, Campus de Gualtar, 4710-057 Braga, Portugal
}

\begin{abstract}
Shelf life extension of Ricotta cheese was evaluated at $4{ }^{\circ} \mathrm{C}$ upon the use of edible coatings made of galactomannans from Gleditsia triacanthos incorporating nisin against Listeria monocytogenes. Three different treatments were tested in cheese: samples without coating; samples with coating without nisin; and samples with coating containing $50 \mathrm{IU} \cdot \mathrm{g}^{-1}$ of nisin. To test the effectiveness of the treatments against $L$. monocytogenes, the surface of the cheese was inoculated with a suspension of the microorganism. Microbiological and physical-chemical analyses of the cheese samples were performed during 28 days. Results showed that the cheese coated with nisin-added galactomannan film was the treatment presenting the best results in terms of microbial growth delay $(p<0.05)$. The addition of nisin also affects $(p<0.05)$ the physical and mechanical properties of the films: $\mathrm{O}_{2}$ permeability decreased from 1.84 to $1.35 \times 10^{-12} \mathrm{~cm}^{3} \cdot(\mathrm{Pa} \cdot \mathrm{s} \cdot \mathrm{m})^{-1} ; \mathrm{CO}_{2}$ permeability increased from 1.96 to $6.31 \times 10^{-12} \mathrm{~cm}^{3} \cdot(\mathrm{Pa} \cdot \mathrm{s} \cdot \mathrm{m})^{-1}$; opacity increased from 3.68 to $4.59 \%$; tensile strength ranged from 0.84 to $1.46 \mathrm{MPa}$; and elongation at break improved from 50.93 to $68.16 \%$. These results demonstrate that novel galactomannan-based edible coatings, when combined with nisin, may provide consumer-friendly alternatives to reduce $L$. monocytogenes postcontamination on cheese products during storage.
\end{abstract}

KEYWORDS: Shelf life; Ricotta cheese; edible coating; galactomannan; nisin; Listeria monocytogenes

\section{INTRODUCTION}

In recent years, research on renewable packaging materials such as polysaccharides (e.g., chitosan and cellulose) and on production methods has increased considerably. Galactomannans are hydrophilic polysaccharides derived from leguminous seeds, possessing main chains based on $(1 \rightarrow 4)$-linked D-mannopyranose units to which $(1 \rightarrow 6)$-linked D-galactopyranose units are attached $(1)$. Galactomannans from nonconventional sources (e.g., from Gleditsia triacanthos) have been used to produce edible films and coatings (2). The importance of these materials has strongly increased because of the global trend to use more plant-based products for ecological reasons. This has put a stress on conventional galactomannan sources such as guar gum and locust bean gum. Seeking new sources of this type of materials for industrial uses could therefore contribute to the effort of reducing the ecological footprint of the food industry. In spite of Gleditsia being widely spread in the southern hemisphere, a significant part of the wide variety of resources offered by this species has not been exploited yet. Galactomannans present inumerous advantageous properties, such as being nontoxic thickening, emulsifying, gelling agents and also featuring film forming properties. Plasticizers, such as glycerol, increase film flexibility and decrease film barrier

*Corresponding author. Phone: + 351.253.604419. Fax: +351.253.678.986. E-mail: avicente@deb.uminho.pt. properties as a result of a decrease in intermolecular forces along neighboring polymer chains (3).

Edible coatings and films have been used to reduce the deleterious effects of various factors, including water loss, microbial growth, and enzymatic browning, among others (4). Edible coatings may also act as carriers of food additives, such as antimicrobials and antioxidants agents, flavors, colorants, and spices (5). Additionally, there is a growing interest in the development of antimicrobial packaging containing natural antimicrobial agents. This interest has been driven by consumers concerns about health-related issues, such as the use of synthetic antimicrobial agents (6). The main group of biopreservatives suggested for this purpose is bacteriocins such as nisin.

Nisin is one of the most studied bacteriocins. It is a small peptide $(3.5 \mathrm{kDa})$ produced by bacteria, with antimicrobial activity against Gram positive bacteria, such as Clostridium botulinum and Listeria monocytogenes (7). The bacteriocin nisin is not generally active against Gram negative bacteria, fungi, and viruses. The use of nisin as a preservative in foods, such as cheese, has been recognized by the FAO/WHO, and the FDA has given it generally recognized as safe (GRAS) status (8). The application of nisin in films to control microbial growth on food products has been investigated $(9,10)$. The use of films containing antimicrobial agents could be more efficient against undesirable microorganisms than direct addition of antimicrobials to the food product (6). 
Soft, white, and fresh cheeses subjected to minimal processing are highly perishable and thus have a short shelf life. Cheese is a ready-to-eat type of food that has been associated with foodborne listeriosis (11). Listeria monocytogenes is psychrotrophic and can grow at refrigeration temperatures, at $\mathrm{pH}$ values of 5.0 and above, in high salt concentrations, while being also relatively resistant to freezing and drying (12). Contamination by this organism could lead to a high risk factor at pre- and especially at postproduction stages (11). Ricotta cheese is a soft Italian cheese typical in Italy and Ibero-American countries. Ricotta cheese can be manufactured from whole or whey milk or a blend of these products. Whole milk Ricotta is a soft and creamy cheese with a delicate texture (13). Ricotta has a high moisture content, and its initial $\mathrm{pH}$ is above 6.0 , thus rendering it susceptible to microbial spoilage; even under refrigeration it has a limited shelf life (14). The heat treatment applied during cheese manufacture is generally sufficient to inactivate small numbers of Listeria that might be present; however, postprocessing contamination can also occur (15). The application of an edible film containing nisin on the cheese surface immediately after processing would thus provide an additional hurdle to reduce the likelihood of postprocessing contamination by L. monocytogenes. This approach prevents the addition of nisin into the bulk of the cheese while improving surface protection. Overall, it contributes to a significant reduction of the amount of nisin needed to prevent foodborne disease by L. monocytogenes.

In this work, Ricotta cheese was coated with galactomannan coatings with or without nisin as antimicrobial agent. The inhibitory activity against $L$. monocytogenes on the surface of coated cheese stored at refrigeration $\left(4^{\circ} \mathrm{C}\right)$ was assessed. The effects of the application of the coatings on the physicochemical and microbial decay of the cheese were evaluated. The physical properties of the edible film with nisin were also investigated.

\section{MATERIALS AND METHODS}

Material. Gleditsia triacanthos seeds were collected in the Botanic Garden in Porto, Portugal, in November 2008. The polysaccharide (galactomannan) extraction from the seeds was performed as described in ref 1. Glycerol (87\%) and ethanol absolute were purchased from Panreac (Spain), and the corn oil was obtained from Sovena (Portugal).

Antimicrobial Effectiveness of the Nisin Solution. Culture Preparation. Listeria monocytogenes CECT 4032 culture (provided by the Spanish Type Culture Collection, Valencia, Spain) was grown for $18 \mathrm{~h}$ in Brain Heart Infusion (BHI) Broth (Liofilchem Diagnostic, Italy) at $37^{\circ} \mathrm{C}(7)$. The inoculum level of this culture (approximately $10^{6} \mathrm{CFU} \cdot \mathrm{mL}^{-1}$ ) was determined by decimal dilutions in peptone water. Microbiological counts $\left(\mathrm{CFU} \cdot \mathrm{mL}^{-1}\right)$ were determined by plating duplicate decimal dilutions of samples on BHI Agar (Liofilchem Diagnostic, Italy) for $24 \mathrm{~h}$ at $37^{\circ} \mathrm{C}$.

Nisin Solution. The nisin was purchased from Sigma-Aldrich $(2.5 \% \mathrm{w} /$ w pure nisin, balance sodium chloride and denatured milk solids, activity of $1 \times 10^{6} \mathrm{IU} \cdot \mathrm{g}^{-1}$, according to the manufacturer). The nisin solution was prepared as described in ref 8 . Briefly, a $10,000 \mathrm{IU} \cdot \mathrm{mL}^{-1}$ (corresponds to a $10 \mathrm{mg} \cdot \mathrm{mL}^{-1}$ ) stock solution was prepared which was then filter-sterilized though a $0.22 \mu \mathrm{m}$ pore filter (Orange Scientific). A 2-fold serial dilution was prepared diluting with $0.02 \mathrm{M} \mathrm{HCl}$ (Panreac, Spain) to obtain a decreased concentration range from 625 to $10,000 \mathrm{IU} \cdot \mathrm{mL}^{-1}$. Concentrations of nisin mentioned here and elsewhere represent pure nisin concentrations. All solutions were stored at $4{ }^{\circ} \mathrm{C}$ until further use. The lowest inhibition concentration of nisin was added to the galactomannan coating formulation.

Disk Diffusion Method. Antimicrobial activity was tested by the disk diffusion method (16). Briefly, $100 \mu \mathrm{L}$ of inoculum containing $10^{6}$ $\mathrm{CFU} \cdot \mathrm{mL}^{-1}$ of $L$. monocytogenes, prepared in the previous step, were spread on the surface of Petri dishes containing BHI agar. Sterile filter paper disks of $0.6 \mathrm{~cm}$ in diameter were placed carefully onto those Petri dishes. Ten microliters of nisin solutions at different concentrations
Table 1. Concentrations of Galactomannan, Glycerol, and Oil Used in the Film Formulations, and Spreading Coefficient $(W)$ Values of the Film-Forming Solutions on Cheese ${ }^{a}$

\begin{tabular}{ccccc}
\hline solution & galactomannan $(\mathrm{w} / \mathrm{v})$ & glycerol $(\mathrm{w} / \mathrm{v})$ & oil $(\mathrm{w} / \mathrm{v})$ & \multicolumn{1}{c}{$W$} \\
\hline 1 & 0.5 & 0.5 & 0 & $-29.28 \pm 2.09 \mathrm{ad}$ \\
2 & 0.5 & 0.5 & 0.5 & $-29.56 \pm 1.43 \mathrm{a}$ \\
3 & 0.5 & 1.5 & 0 & $-22.54 \pm 1.75 \mathrm{be}$ \\
4 & 0.5 & 1.5 & 0.5 & $-28.16 \pm 0.67 \mathrm{ae}$ \\
5 & 1.0 & 1.0 & 0.25 & $-27.97 \pm 0.99 \mathrm{ae}$ \\
6 & 1.5 & 0.5 & 0 & $-42.05 \pm 0.82 \mathrm{cf}$ \\
7 & 1.5 & 0.5 & 0.5 & $-47.25 \pm 1.48 \mathrm{c}$ \\
8 & 1.5 & 1.5 & 0 & $-44.81 \pm 1.75 \mathrm{cf}$ \\
9 & 1.5 & 1.5 & 0.5 & $-39.86 \pm 1.66 \mathrm{df}$ \\
\hline
\end{tabular}

${ }^{a}$ Values reported are the means \pm standard deviations. Different letters in the same column indicate a statistically significant difference (Tukey test, $p<0.05$ ).

$\left(0-5.0 \mathrm{mg} \cdot \mathrm{mL}^{-1}\right)$ prepared by a series of dilutions were then dispensed into the disks. Sterile distilled water was used as control. The plates were refrigerated for $3 \mathrm{~h}$ to permit diffusion of nisin and afterward incubated at $37{ }^{\circ} \mathrm{C}$ for $24 \mathrm{~h}$. The diameter of inhibition zones around the disks (including the paper disk itself) was determined with a Vernier Caliper (Series 530, Mitutoyo, Manufacturing Co., Ltd., Japan)-the experiment was conducted in duplicate. The minimal inhibitory concentration (MIC) of nisin was selected for application in the edible coatings.

Preparation of Coating-Forming Solutions. Coating-forming solutions were prepared using a $3^{3}$ factorial design: galactomannan at $0.5 \%$, $1.0 \%$, and $1.5 \%(\mathrm{w} / \mathrm{v})$, glycerol at $0.5 \%, 1.0 \%$, and $1.5 \%(\mathrm{w} / \mathrm{v})$, and corn oil at $0 \%, 0.25 \%$, and $0.5 \%(\mathrm{w} / \mathrm{v})$. The addition of oil to a coating-forming solution contributes to the improvement of their barrier properties. Water vapor barrier properties are reported to be reduced by the presence of lipids, as observed by Cerqueira et al. (2). Galactomannan and glycerol (plasticizer) were added to water and stirred for $2 \mathrm{~h}$ at $20^{\circ} \mathrm{C}$. Film-forming solutions were emulsified with corn oil, which was dispersed through agitation during $20 \mathrm{~min}$ at $60{ }^{\circ} \mathrm{C}$. The concentration values for each formulation are shown in Table 1 . These concentrations were chosen based on previous works in cheese (2). Wettability values were used to choose the most appropriate coating formulation.

Two types of coatings were developed and applied on cheese for shelf life and film characterization: galactomannan and glycerol solutions with and without nisin were homogenized using an Ultra-Turrax T25 homogenizer ( $\mathrm{T}$ 25, Ika-Werke, Germany), for $2 \mathrm{~min}$ at 10,000 rpm. The concentration of nisin used was based on the results obtained in MIC determinations. The activity of pure nisin per film was $50 \mathrm{IU} \cdot \mathrm{g}^{-1}$, corresponding to $0.05 \mathrm{mg}$ nisin per gram of dried film.

Films were prepared by pouring $28 \mathrm{~mL}$ of the film-forming solution onto a $9 \mathrm{~cm}$ diameter Petri dish. The films were dried in an oven at $35^{\circ} \mathrm{C}$ for $16 \mathrm{~h}$ and stored at $20^{\circ} \mathrm{C}$ and $50 \% \mathrm{RH}$, until further use.

Wettability. To evaluate the capacity of the solutions to coat the cheese surface, the wettability was determined. Both contact angle and surface tension were determined with a face contact angle meter (OCA 20, Dataphysics, Germany). The surface tension of the coating solution was measured by the pendent drop method and the Laplace-Young approximation (3). The contact angle was measured by the sessile drop method. Twenty replicates of contact angle and surface tension measurements were analyzed at $20 \pm 1{ }^{\circ} \mathrm{C}$. The coating presenting the better values of wettability was chosen for the shelf life determinations and film characterization (Table 1).

Film Characterization. Film Thickness. Film thickness was measured with a micrometer (No. 293-5, Mitutoyo Manufacturing Co., Ltd., Japan) to the nearest $0.001 \mathrm{~mm}$ at three random positions. These values were used to calculate the water vapor permeability (WVP), mechanical properties, and $\mathrm{O}_{2}$ and $\mathrm{CO}_{2}$ permeability.

Film Color and Opacity. Color was determined in triplicate using a colorimeter (CR-400; Minolta, Japan). The films were superposed on a white standard $\left(L^{*}=84.67, a^{*}=-0.55\right.$, and $\left.b^{*}=0.68\right)$, which recorded the spectrum of reflected light and converted it into a set of color coordinates ( $L^{*}, a^{*}$, and $b^{*}$ values) (2). Using the equipment software, opacity was calculated as the relationship between the opacity of the film superposed on the black standard $\left(P_{\text {black }}\right)$ and the film superposed on the 
white standard $\left(P_{\text {white }}\right)$, according to eq $\mathbf{1}$ :

$$
\text { Opacity }=\frac{P_{\text {black }}}{P_{\text {white }}} \times 100
$$

Tensile Strength and Elongation. The films' tensile strength (TS) and elongation at break $(E)$ were determined using an Instron Universal Testing Machine (model 4484; Instron Co., Canton, MA) according to the ASTM D882-91 standard method (17). The film specimens were conditioned in an environmental chamber at $25{ }^{\circ} \mathrm{C}$ and $50 \% \mathrm{RH}$ for 2 days. An initial grip distance of $30 \mathrm{~mm}$ and crosshead speed of $5 \mathrm{~mm} \cdot \mathrm{min}^{-1}$ were used. The TS was calculated by dividing the maximum load $(N)$ by the initial film cross-sectional area $\left(\mathrm{m}^{2}\right)$ of the film. $E$ was expressed as a percentage of the change in the initial length of the specimen at the point of break. Each determination was taken from an average of five specimens.

Water Vapor Permeability (WVP). The WVP was determined according to a method proposed by Kristo et al. (6), based on the ASTM E9663T. The edible films were firmly fixed onto the opening of test cells containing distilled water $\left(100 \% \mathrm{RH} ; 2337 \mathrm{~Pa}\right.$ vapor pressure at $\left.20^{\circ} \mathrm{C}\right)$. Then, these cells were placed in a desiccator $(0 \% \mathrm{RH} ; 0 \mathrm{~Pa}$ water vapor pressure at $20^{\circ} \mathrm{C}$ ) containing silica gel. Each cell was weighed every $2 \mathrm{~h}$ for $10 \mathrm{~h}$ using an analytical balance ( $0.0001 \mathrm{~g}$ accuracy), to record moisture loss over time. The WVP was calculated by linear regression from the points of weight loss and time, in the constant rate period. To maintain the air circulation constant outside the test cell, a miniature fan was used inside the desiccator. Therefore, uniform water pressure conditions and steadystate were assumed. All tests were made in triplicate.

$\mathrm{O}_{2}$ and $\mathrm{CO}_{2}$ Permeability. Oxygen permeability $\left(\mathrm{P}\left(\mathrm{O}_{2}\right)\right)$ and carbon dioxide permeability $\left(P\left(\mathrm{CO}_{2}\right)\right)$ were determined according to the ASTM D 3985-02 method described by Cerqueira et al. (2).

Oxygen permeability $\left(P\left(\mathrm{O}_{2}\right)\right)$ was measured at $20 \pm 2{ }^{\circ} \mathrm{C}$ and $50 \pm 1 \%$ $\mathrm{RH}$ using an $\mathrm{O}_{2}$ sensor (Mettler-Toledo, Switzerland). $\left(P\left(\mathrm{O}_{2}\right)\right)$ was obtained by multiplying the oxygen transmission rate (OTR) by the film thickness and dividing by the oxygen partial pressure difference $(\Delta P)$. Three replicates were obtained for each film.

Carbon dioxide permeability $\left(P\left(\mathrm{CO}_{2}\right)\right)$ was determined by gas chromatography (Chrompack 9001, Middelburg, Netherlands) with a column Porapak Q 80/100 mesh $2 \mathrm{~m} \times 1 / 8^{\prime \prime} \times 2 \mathrm{~mm} \mathrm{SS}$ to separate the $\mathrm{CO}_{2}$ and with a column molecular sieve 5A 80/100 mesh $1 \mathrm{~m} \times 1 / 8^{\prime \prime} \times 2 \mathrm{~mm}$ to separate the $\mathrm{O}_{2}$ followed by a thermal conductivity detector (TCD) at $110^{\circ} \mathrm{C}$. Helium at $23 \mathrm{~mL} \cdot \mathrm{min}^{-1}$ was used as carrier gas. A mixture containing $10 \% \mathrm{CO}_{2}, 20 \% \mathrm{O}_{2}$, and $70 \% \mathrm{~N}_{2}$ was used as the standard for calibration. Three replicates of each condition were evaluated.

Effect of Galactomannan-Coated Film on the Growth of Listeria monocytogenes on Ricotta Cheese. Preparation of Cheese. Ricotta cheese preparation is described in ref 14 . Briefly, Ricotta cheese was made from pasteurized whole cow's milk provided by a local farm (São Estevão de Penso, Braga, Portugal). The temperature was increased to $90{ }^{\circ} \mathrm{C}$, and acetic acid (white vinegar, Gallo, Portugal) was added to the milk (25 $\left.\mathrm{mL} \cdot \mathrm{L}^{-1}\right)$, during which the curd precipitated. The cheese was collected in molds ( $43 \mathrm{~mm}$ diameter round pieces, $20 \mathrm{~mm}$ height) to partially eliminate whey. After cooling at ambient temperature, their weights were recorded.

Inoculation and Coating of Inoculated Cheese Samples. L. monocytogenes was grown overnight at $37^{\circ} \mathrm{C}$ in $\mathrm{BHI}$ broth. The culture was diluted to $10^{6} \mathrm{CFU} \cdot \mathrm{mL}^{-1}$, thus serving as inoculum to be used on the cheese samples. Three different treatments were tested: a cheese sample without coating (C); a sample with a coating $(0.5 \%(\mathrm{w} / \mathrm{v})$ of galactomannan and $1.5 \%(\mathrm{w} / \mathrm{v})$ of glycerol) without nisin added (N0), and a sample with a coating $(0.5 \%(\mathrm{w} / \mathrm{v})$ of galactomannan and $1.5 \%(\mathrm{w} / \mathrm{v})$ of glycerol) with 50 $\mathrm{IU} \cdot \mathrm{g}^{-1}$ nisin added $(\mathrm{N})$. Coating solutions were previously sterilized under UV light ( $254 \mathrm{~nm}$ ) during 2 min prior to being applied to cheese samples. Circular cheese samples of approximately $20 \mathrm{~g}$ (43 mm diameter and 20 $\mathrm{mm}$ height) were dipped into the pertinent coating solution for $30 \mathrm{~s}$ and dried for $1 \mathrm{~h}$ in a vertical laminar airflow bench to ensure surface dryness. Dried cheeses were then inoculated with $50 \mu \mathrm{L}$ of L. monocytogenes inoculum, and stored at $4 \pm 2{ }^{\circ} \mathrm{C}$ for 28 days in a cooled chamber at $75 \%$ relative humidity (RH). Unpacked cheese samples stored at similar conditions were used as control. Cheese samples were analyzed microbiologically and physicochemically at regular intervals $(0,2,7,14,21$, and 28 days).

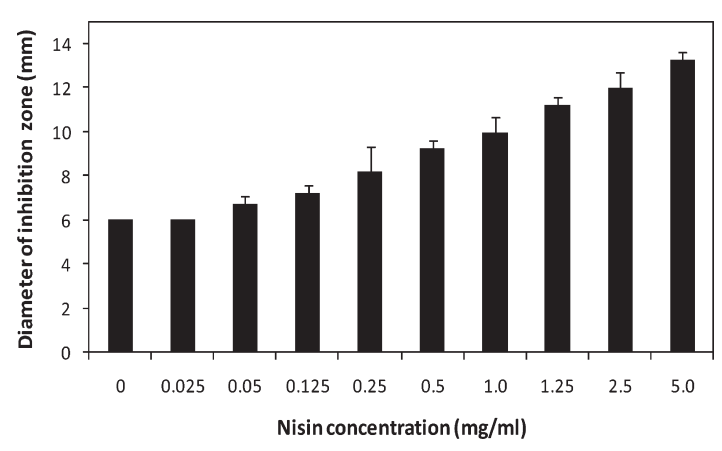

Figure 1. Diameter of the inhibition zones $(\mathrm{mm})$ produced by nisin in the disk diffusion assay. Error bars represent the standard deviation obtained in duplicate experiments.

Effect of Nisin-Added Film on Shelf Life of Cheese Samples. Physicochemical Analyses. The $\mathrm{pH}$ value of each sample was measured with a $\mathrm{pH}$ meter 620 (Methohm, Switzerland). The $\mathrm{pH}$ electrode was inserted into the cheese sample for $\mathrm{pH}$ measurement. These measurements were performed in each sample day.

Weight loss was evaluated by weighing all samples with a Mettler AE200 precision balance $( \pm 0.0001 \mathrm{~g})$ at the beginning of storage (day 0$)$ and at 2, 7, 14, 21, and 28 days of storage. The difference between the two values was considered as the weight loss.

Moisture content was determined by measuring the weight loss at $105^{\circ} \mathrm{C}$ until constant weight.

Surface color was measured during storage using a colorimeter (CR400; Minolta, Japan) appropriately calibrated with a standard white tile (UE certificated) with the following parameters: $X=83.47, Y=84.43$, and $Z=95.16$ with illuminant $\mathrm{C} / 2$ (light source used for the daylight), according to the CIE $L^{*}, a^{*}$, and $b^{*}$ scale. The total color difference $(\Delta E)$ was determined according to eq $\mathbf{2}$ :

$$
\Delta E=\left[\left(\Delta L^{*}\right)^{2}+\left(\Delta a^{*}\right)^{2}+\left(\Delta b^{*}\right)^{2}\right]^{0.5}
$$

Microbiological Analyses. For microbiological analyses, cheese samples $(20 \mathrm{~g})$ were transferred into individual sterile stomacher bags, mixed with $225 \mathrm{~mL}$ of $0.1 \%$ peptone water (Becton, Dickinson and Company, France), and homogenized in a Stomacher 3500 (Seward Medical, U.K.) for $2 \mathrm{~min}$. At each sampling day, two samples were analyzed per treatment. For each sample, appropriate serial decimal dilutions were prepared in peptone water and then plated by spreading $0.1 \mathrm{~mL}$ in duplicate on the surface of dry media. L. monocytogenes was enumerated on Oxford agar base (Biokar Diagnostics) plates, after incubation at $30^{\circ} \mathrm{C}$ for $48 \mathrm{~h}$. Black colonies on the plates were counted $(9,15)$. Microbiological counts were converted to $\log \mathrm{CFU} \cdot \mathrm{g}^{-1}$, and the means and standard deviations were calculated.

Statistical Analyses. Data from the repeated experiments were analyzed to determine whether the variances were statistically homogeneous. The results were expressed as means \pm SD. Statistical comparisons were made by one-way analysis of variance (ANOVA) followed by a Tukey's multiple comparisons test using Microsoft Windows Excel 2007 and SigmaPlot 11.0 for Windows. Statistica software (release 7, edition 2004, Statsoft, Tulsa, OK) was used to create a $3^{3}$ factorial design with a center point. Differences were considered to be significant when the $p$ values were under 0.05 .

\section{RESULTS AND DISCUSSION}

Disk Diffusion Assay. The disk diffusion technique was the procedure used for quantification and establishment of the lowest level of nisin necessary for antimicrobial activity. Figure 1 summarizes the antimicrobial activity of nisin expressed in terms of the diameter of the inhibition zone observed in growth media where the test microorganism was previously inoculated. The upper limit of nisin concentration used in this assay was based on the maximum value allowed $\left(10 \mathrm{mg} \cdot \mathrm{g}^{-1}\right)$ in cheese $(8)$. Increasing concentrations of nisin increased the diameter of the growth inhibition zone (see Figure 1). The degree of inhibition of $L$. 
monocytogenes by different nisin concentrations was used to determine the MIC as $0.05 \mathrm{mg} \cdot \mathrm{mL}^{-1}$ (the concentration corresponds to an activity of $50 \mathrm{IU} \cdot \mathrm{mL}^{-1}$ ), which was the lowest dilution resulting in the complete inhibition of L. monocytogenes. Singh et al. (18) also found that the MIC of nisin for different strains of L. monocytogenes was $50 \mathrm{IU} \cdot \mathrm{mL}^{-1}$. Based on these MIC values, the amount of nisin used in the film was $50 \mathrm{IU} \cdot \mathrm{g}_{\text {film. }}^{-1}$.

Wettability of Polysaccharide Solutions on Cheese. Contact angles of a liquid over a solid are an indicator of the surface hydrophobicity or the wettability of the coatings. Wettability is one of the main parameters used to optimize the composition of coating solutions to be applied on a specific foodstuff (19). The other parameters are the adhesion coefficient (a measure of the forces which promote the spreading of the liquid) and cohesion coefficient (a measure of the forces which promote its contraction).

The wettability was studied by determining the values of the spreading coefficient $(W)$. The best value of $W$ (values closer to zero) on the cheese surface was determined for the different concentrations of galactomannan, glycerol, and oil. $W$ values are influenced by the compatibility of the polarity of the film solutions and that of the cheese surface (apolar) (2).

The results in Table 1 show that $W$ decreased as the galactomannan concentration increased for the cheese studied. The same was observed when the oil concentration decreased. The solutions with higher values of $W$ were those containing glycerol. Casariego et al. (3) reported that the addition of plasticizer affected the structure, texture, and surface properties of coatings when applied to tomato and carrot. Although there were no significant differences $(p>0.05)$ between the solutions presenting higher $W$ values (solutions 3, 4, and 5), solution 3 ( $W=-22.54 \pm 1.75)$ was chosen to be subsequently analyzed and applied on cheese because it showed the value of $W$ which was closest to zero. As previously stated, oil addition contributes to the reduction of WVP; however, coating adhesion to the surface of the cheese was given a higher priority when selecting a coating formulation solution. This choice has been made once it is fundamental that the coating is well spread over the surface, with no uncoated areas or cracks. This occurrence would allow a higher mass transfer rate of gases, eventually annulling the gain in WVP achieved by the eventual presence of oil. Consequently, the formulations containing oil were not chosen to proceed with further testing, since the oil-free solution $3(0.5 \%$ (w/v) galactomannan and $1.5 \%(\mathrm{w} / \mathrm{v})$ glycerol $)$ was the one presenting the lowest value of $W$.

Film Characterization. Determination of Film Color and Opacity. The optical properties of the films are important since they have a direct impact on the appearance of the coated product. Opacity is an important feature for the quality preservation of foods. Films should have high barrier performances against the light incidence in order to avoid harmful light-catalyzed reactions (20). However, a good transparency is essential for consumer's acceptability of the food. Galactomannan films without nisin (N0) were transparent and slightly yellow. Their transparency was reduced as the antimicrobial agent was incorporated (Table 2). Galactomannan film incorporating nisin $(\mathrm{N})$ at 50 $\mathrm{IU} \cdot \mathrm{g}^{-1}$ revealed opacity values of $4.59 \pm 0.91 \%$, higher $(p<$ $0.05)$ than those obtained for $\mathrm{N} 0(3.68 \pm 0.21 \%)$. This is possibly caused by the dispersion of glycerol and nisin in the galactomannan matrix; however, this possibility is yet to be confirmed.

The $L^{*}, a^{*}$, and $b^{*}$ values were also measured (Table 2). The incorporation of nisin did not have a significant influence $(p>0.05)$ on the color parameters of the galactomannan film. Sivarooban et al. (21) obtained similar results with nisin addition to soy protein edible films.
Table 2. Thickness, Opacity, Color, WVP, $P\left(\mathrm{O}_{2}\right), P\left(\mathrm{CO}_{2}\right)$, TS, and $E$ of Galactomannan-Glycerol and Nisin-Added Edible Films

\begin{tabular}{|c|c|c|}
\hline & \multicolumn{2}{|c|}{ treatment $^{a}$} \\
\hline & No & $\mathrm{N}$ \\
\hline thickness (mm) & $0.078 \pm 0.050 \mathrm{a}$ & $0.095 \pm 0.122 b$ \\
\hline opacity (\%) & $3.68 \pm 0.21 \mathrm{a}$ & $4.59 \pm 0.91 b$ \\
\hline$L^{*}$ & $89.26 \pm 1.76 \mathrm{a}$ & $89.73 \pm 1.54 \mathrm{a}$ \\
\hline$a^{*}$ & $5.24 \pm 0.29 a$ & $5.09 \pm 0.18 a$ \\
\hline$b^{\star}$ & $11.56 \pm 2.15 a$ & $9.85 \pm 2.17 \mathrm{a}$ \\
\hline WVP $\times 10^{-6}\left(\mathrm{~cm}^{3} \cdot(\mathrm{Pa} \cdot \mathrm{s} \cdot \mathrm{m})^{-1}\right)$ & $7.30 \pm 0.64 \mathrm{a}$ & $6.52 \pm 0.49 \mathrm{a}$ \\
\hline$P\left(\mathrm{O}_{2}\right) \times 10^{-12}\left(\mathrm{~cm}^{3} \cdot(\mathrm{Pa} \cdot \mathrm{s} \cdot \mathrm{m})^{-1}\right)$ & $1.84 \pm 0.19 a$ & $1.35 \pm 0.22 b$ \\
\hline$P\left(\mathrm{CO}_{2}\right) \times 10^{-12}\left(\mathrm{~cm}^{3} \cdot(\mathrm{Pa} \cdot \mathrm{s} \cdot \mathrm{m})^{-1}\right)$ & $1.96 \pm 0.32 a$ & $6.31 \pm 1.19 b$ \\
\hline tensile strength (TS) (MPa) & $0.84 \pm 0.08 \mathrm{a}$ & $1.46 \pm 0.29 b$ \\
\hline elongation at break $(E)(\%)$ & $50.93 \pm 6.72 \mathrm{a}$ & $68.16 \pm 10.04 b$ \\
\hline
\end{tabular}

${ }^{a} \mathrm{~N} 0$, no nisin added; $\mathrm{N}$, nisin added. Values reported are the means \pm standard deviations. Different letters in the same row indicate a statistically significant difference (Tukey test, $p<0.05$ ).

Measurement of Thickness, Tensile Strength (TS), and Elongation $(E)$. The incorporation of nisin increased film thickness from $0.078 \mathrm{~mm}$ (obtained for films without nisin: N0) to $0.095 \mathrm{~mm}$. An improved thickness could be explained by the increase of the total weight of the film-forming solution. Also, hydrophobic interactions favored by nisin molecules in the filmforming solution could increase its thickness. Ko et al. (7) reported that nisin (hydrophobic) incorporated into soy protein film-forming solution (hydrophilic/hydrophobic properties) forms larger clusters in the film matrix, increasing film thickness.

Suitable mechanical strength and extensibility are generally required for a film to resist external stress and maintain its integrity during processing, packaging, shipping, and storage. Tensile strength (TS) and percentage of elongation at break (E) are parameters that relate mechanical properties of films to their chemical structures. Since temperature and humidity can have profound effects on the mechanical properties of films, tensile testing should be conducted under controlled environmental conditions. The addition of nisin led to a significant reduction $(p<0.05)$ of TS (Table 2). N0 and N presented TS values of 0.838 and $1.46 \mathrm{MPa}$, respectively. This increase of TS could be explained by the incorporation of nisin into films that might have caused a network formation between nisin and polysaccharide molecules. However, Sivarooban et al. (21) showed that nisin added to protein based films decreased TS from 8.80 to $5.11 \mathrm{MPa}$. The addition of nisin significantly $(p<0.05)$ affected elongation at break $(E)$ (Table 2). Percentage $E$ for the control film was $50.93 \%$, and that for the nisin-added film was $68.16 \%$. Pranoto et al. (5) reported that the incorporation of nisin in chitosan films increased $E$ values. In this way, the addition of nisin to galactomannan films results in a significant improvement of the film's mechanical properties.

Water Vapor Permeability (WVP) and $\mathrm{O}_{2}$ and $\mathrm{CO}_{2}$ Permeability. WVP evaluates the effectiveness of a film as a barrier to water. It is particularly important for the present work, since the main goal is to avoid or decrease water loss. Several variables have been shown to influence water vapor permeability, including film composition, film thickness, and film preparation technique (22).

The addition of nisin decreases the WVP of galactomannan films without a statistically significant difference (Table 2). This is probably due to its smaller molecular size or lower concentration in the film matrix. Kristo et al. (6) also reported that nisin addition provoked no change in the values of WVP of nisinincorporated sodium caseinate films. Water vapor barrier properties are reported to be improved by the presence of hydrophobictype physical obstacles (23). Cerqueira et al. (17) obtained a lower 
Table 3. Values of $\mathrm{pH}$ of Ricotta Cheese Samples during 28 days Storage at $4{ }^{\circ} \mathrm{C}^{a}$

\begin{tabular}{lccccrr}
\hline & \multicolumn{5}{c}{ storage time (days) } \\
\cline { 2 - 6 } treatment & 0 & 2 & 7 & 14 & 21 & 28 \\
\hline C & $5.47 \pm 0.16$ & $5.53 \pm 0.15$ & $5.51 \pm 0.03$ & $5.58 \pm 0.03$ & $5.72 \pm 0.03$ & $6.63 \pm 0.23$ \\
N0 & $5.60 \pm 0.00$ & $5.48 \pm 0.03$ & $5.50 \pm 0.00$ & $5.61 \pm 0.03$ & $5.68 \pm 0.03$ & $6.43 \pm 0.06$ \\
N & $5.60 \pm 0.00$ & $5.42 \pm 0.03$ & $5.57 \pm 0.06$ & $5.67 \pm 0.06$ & $5.90 \pm 0.17$ & $6.47 \pm 0.12$ \\
\hline
\end{tabular}

${ }^{a} \mathrm{C}$, sample without coating; N0, no nisin added; $\mathrm{N}$, nisin added. Values reported are the means \pm standard deviations.

Table 4. Values of $L^{*}, a^{*}, b^{*}$, and Color Difference $(\Delta E)$ of Ricotta Cheese Samples during 28 days Storage at $4{ }^{\circ} C^{a}$

\begin{tabular}{|c|c|c|c|c|c|c|c|}
\hline & \multirow[b]{2}{*}{ treatment } & \multicolumn{6}{|c|}{ storage time (days) } \\
\hline & & 0 & 2 & 7 & 14 & 21 & 28 \\
\hline \multirow[t]{3}{*}{$L^{*}$} & C & $93.36 \pm 3.07 \mathrm{a}$ & $65.18 \pm 1.60 a$ & $63.80 \pm 1.11 \mathrm{a}$ & $61.78 \pm 3.65 a$ & $55.03 \pm 1.25 a$ & $52.79 \pm 0.36 a$ \\
\hline & NO & $92.62 \pm 0.76 a$ & $65.60 \pm 1.59 a$ & $64.83 \pm 1.23 a$ & $63.91 \pm 3.00 \mathrm{a}$ & $61.25 \pm 1.04 a b$ & $58.12 \pm 2.31 \mathrm{a}$ \\
\hline & $\mathrm{N}$ & $91.55 \pm 0.46 a$ & $65.66 \pm 0.38 a$ & $65.39 \pm 0.20 a$ & $64.56 \pm 1.26 a$ & $62.18 \pm 0.66 b$ & $60.38 \pm 1.20 b$ \\
\hline \multirow[t]{3}{*}{$a^{*}$} & C & $2.40 \pm 0.14 a$ & $1.57 \pm 0.13 a$ & $1.53 \pm 0.13 a$ & $2.22 \pm 0.06 a$ & $5.16 \pm 0.56 a$ & $5.27 \pm 0.71 \mathrm{a}$ \\
\hline & No & $2.51 \pm 0.18 \mathrm{a}$ & $2.01 \pm 0.08 b$ & $1.78 \pm 0.12 a b$ & $2.58 \pm 0.18 b$ & $1.40 \pm 0.10 b$ & $1.67 \pm 0.11 b$ \\
\hline & $\mathrm{N}$ & $2.41 \pm 0.25 a$ & $2.00 \pm 0.09 b$ & $2.00 \pm 0.23 b$ & $3.45 \pm 0.26 c$ & $1.60 \pm 0.09 b$ & $2.12 \pm 0.44 b$ \\
\hline \multirow[t]{3}{*}{$b^{*}$} & $\mathrm{C}$ & $7.29 \pm 0.65 a$ & $5.34 \pm 0.18 a$ & $4.72 \pm 0.44 \mathrm{a}$ & $5.44 \pm 0.88 a$ & $14.53 \pm 1.48 \mathrm{a}$ & $16.08 \pm 2.19 a$ \\
\hline & NO & $6.23 \pm 0.35 b$ & $4.87 \pm 0.43 a$ & $7.06 \pm 0.20 b$ & $9.35 \pm 0.59 b$ & $7.27 \pm 0.83 b$ & $4.68 \pm 0.27 b$ \\
\hline & $\mathrm{N}$ & $8.97 \pm 0.68 c$ & $6.83 \pm 0.65 b$ & $7.31 \pm 0.62 b$ & $15.39 \pm 1.19 c$ & $7.88 \pm 0.48 b$ & $5.26 \pm 0.73 b$ \\
\hline \multirow[t]{3}{*}{$\Delta E$} & $\mathrm{C}$ & $0.00 \pm 0.00 \mathrm{a}$ & $28.26 \pm 1.60 a$ & $29.69 \pm 1.10 \mathrm{a}$ & $31.65 \pm 3.64 a$ & $37.08 \pm 1.07 a$ & $39.57 \pm 0.61 \mathrm{a}$ \\
\hline & NO & $0.00 \pm 0.00 \mathrm{a}$ & $27.06 \pm 1.57 \mathrm{a}$ & $27.81 \pm 1.22 b$ & $28.88 \pm 2.91 \mathrm{a}$ & $32.14 \pm 1.04 b$ & $35.35 \pm 2.29 b$ \\
\hline & $\mathrm{N}$ & $0.00 \pm 0.00 \mathrm{a}$ & $27.38 \pm 0.77 a$ & $26.22 \pm 0.23 b$ & $27.78 \pm 1.35 a$ & $30.50 \pm 0.67 b$ & $32.26 \pm 1.17 c$ \\
\hline
\end{tabular}

${ }^{a} \mathrm{C}$, sample without coating; N0, no nisin added; $\mathrm{N}$, nisin added. Values reported are the means \pm standard deviations. Different letters in the same column indicate a statistically significant difference (Tukey test, $p<0.05$ ).

WVP value of $3.62 \times 10^{-6}\left(\mathrm{~cm}^{3} \cdot(\mathrm{Pa} \cdot \mathrm{s} \cdot \mathrm{m})^{-1}\right)$ for films of Caesalpinia pulcherrima $(0.5 \% \mathrm{w} / \mathrm{v})$ with glycerol $(1.5 \% \mathrm{w} / \mathrm{v})$. Cerqueira et al. (2) reported a WVP of $2.35 \times 10^{-6}\left(\mathrm{~cm}^{3} \cdot(\mathrm{Pa} \cdot \mathrm{s} \cdot \mathrm{m})^{-1}\right)$ for films of chitosan $(0.5 \% \mathrm{w} / \mathrm{v})$ with glycerol $(2.0 \% \mathrm{w} / \mathrm{v})$.

Commonly, polysaccharide films are likely to be good oxygen barriers (24), since their hydrogen-bonded network structure is firmly packed and arranged. Oxygen permeability $\left(P\left(\mathrm{O}_{2}\right)\right)$ values of $\mathrm{N} 0$ and $\mathrm{N}$ are summarized in Table 2. The $P\left(\mathrm{O}_{2}\right)$ of $\mathrm{N} 0$ films was higher than that of $N$. Several factors may be responsible for these differences. The decrease in the $P\left(\mathrm{O}_{2}\right)$ might have been due to the small molecule size of nisin; it has the ability to effectively fill in small empty spaces in the polymer matrix, thus possibly hindering $\mathrm{O}_{2}$ migration.

Carbon dioxide permeability $\left(P\left(\mathrm{CO}_{2}\right)\right)$ is also an important film characteristic. $\mathrm{N}$ films showed higher values $(p<0.05)$ of $P\left(\mathrm{CO}_{2}\right)$ than the $\mathrm{N} 0$ film (Table 2). A similar behavior of $P\left(\mathrm{CO}_{2}\right)$ was observed for carboxymethylcellulose-based edible films incorporating murta leaves extracts (22). The high diffusivity of $\mathrm{CO}_{2}$ through $\mathrm{N}$ films is due probably to the interactions between $\mathrm{CO}_{2}$ nonpolar molecules and apolar nisin molecules.

Effect of Nisin on the Shelf Life of Cheese Samples. Physicochemical Analyses. The effects of nisin addition to the coatings on $\mathrm{pH}$, color, weight loss, and moisture content of the Ricotta cheese are summarized in Tables $\mathbf{3}$ and $\mathbf{4}$ and in Figure 2, respectively.

The initial $\mathrm{pH}$ of the $\mathrm{C}$ sample was 5.47, and the corresponding value for $\mathrm{N}$ was 5.6 (Table 3). On the last day of storage, the $\mathrm{pH}$ values of $\mathrm{C}$ and $\mathrm{N}$ were 6.63 and 6.47, respectively. No significant differences $(p>0.05)$ were observed between the $\mathrm{pH}$ values of the $\mathrm{C}$ sample and the those of treated samples (N0 and $\mathrm{N}$ ) during storage. The slight increase of $\mathrm{pH}$ during the shelf life of Ricotta cheese could be due to the liberation of alkaline compounds during proteolysis. Morgan et al. (25) also observed an increase of $\mathrm{pH}$ during manufacture, ripening, and storage of goat cheese. This fact is a consequence of the alkalizing effect of the compounds generated during protein degradation, due to the presence of microorganisms at the surface. The slight effect of the coating retarding $\mathrm{pH}$ increase with storage, though not statistically distinguishable from the behavior of uncoated cheese, may be attributed to the barrier properties of the coating. In fact, its selective permeability to $\mathrm{O}_{2}$ and $\mathrm{CO}_{2}$ may influence the course of proteolysis, especially if it is considered that this reaction is directly connected to microbial activity.

Samples without coating (C) presented the highest weight loss percentage $(7.59 \pm 0.71 \%)$ while $\mathrm{N}$ showed the lowest weight loss percentage $(4.74 \pm 0.38 \%)$ after 28 days of storage (Figure 2A). Cerqueira et al. (24) observed a decrease (3.8\%) in weight loss of "Regional" Cheese coated with galactomannan. These results are in agreement with the value of moisture content obtained here.

Samples without coating registered the highest losses of moisture content compared with the treatments N0 and N (Figure 2B). There was a significant difference of moisture content between $\mathrm{N}$ $(50.53 \pm 1.67 \%)$ and $\mathrm{N} 0(37.63 \pm 1.55 \%)$ coated cheeses after 2 days of storage. The differences may be attributed to the nisinadded coating, which seems to have retarded moisture loss. Possibly, nisin (hydrophobic) acted as a barrier that slowed-down the movement of water vapor across the film. These results are in agreement with the values observed for WVP (Table 2), where the nisin incorporation decreased the values of WVP of the galactomannan films. According to Tzoumaki et al. (26), hydrophobic compounds such as stearic acid and sucrose fatty acid ester present in sodium carboxymethyl-cellulose and pullulan edible coatings could reduce the weight loss of the surface of white asparagus spears. It should be reported that the moisture content of the cheese samples did not have a noticeable effect on coating adhesion. However, the influence of moisture content on coating adhesion is a matter that may need further attention in future work.

The color of the cheese samples was white just prior to coating application. After coating, N0 and N samples remained white but became glossier than $\mathrm{C}$ samples. Visual evaluation also confirmed that the N0 sample was perceived to have a similar gloss and color to $\mathrm{N}$ samples. 

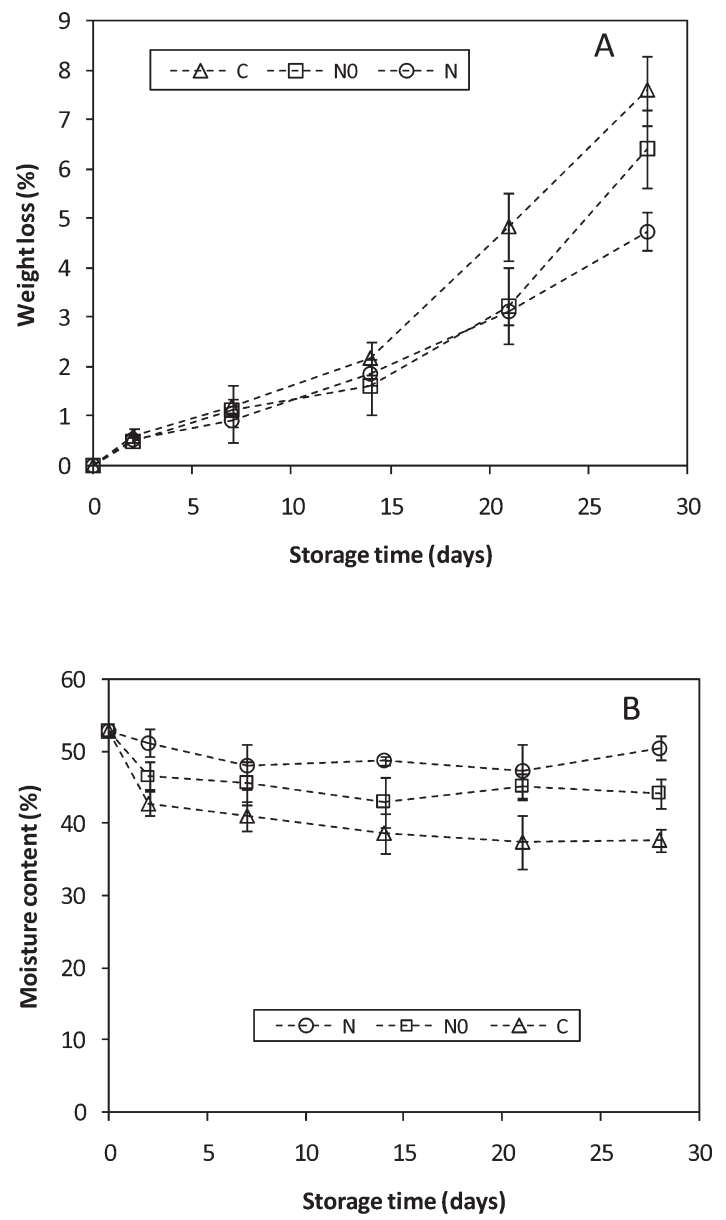

Figure 2. Cheese weight loss (A) and moisture content (B) throughout storage time for cheese samples without coating (C), cheese with coating (N0), and cheese with nisin-added coating (N). Error bars represent the standard deviation.

The $L^{*}, a^{*}$, and $b^{*}$ values of $\mathrm{C}$ samples were in agreement with those found by Pizzillo et al. (27) (Table 4). $L^{*}$ values of C samples showed no significant differences on day 0 when compared to $\mathrm{N}$ samples. However, the $L^{*}$ values of $\mathrm{N}$ samples, at day 28, were higher $(p<0.05)$ than those of $\mathrm{C}$ samples. This observation can be explained by the water loss of the cheese (28). Dried cheeses become yellower with time, imparting Ricotta cheese an unattractive yellow color. In fact, $\mathrm{N}$ samples presented a lighter and less yellow appearance (higher $L^{*}$ values and lower $b^{*}$ values) after 28 days of storage when compared to $\mathrm{C}$ samples (Table 4).

The $\Delta E$ exhibited a fast increase during the first 2 days of storage and then a gradual increase during the remaining storage period (Table 4). This result was obvious for all samples, with the greatest variability being noted for $\mathrm{C}$ samples. An increase of $\Delta E$ values during the shelf life of cheese has been reported previously (29). Incorporation of nisin to the film did significantly decrease the $\Delta E$ of cheese samples $(p<0.05)$ (Table 4). However, Pranoto et al. (5) reported that the incorporation of nisin at $204,000 \mathrm{IU} \cdot \mathrm{g}^{-1}$ in chitosan films increased $\Delta E$ compared to the control. These differences could be due to the smaller amount of nisin used in the present work.

Microbiological Analyses. The antimicrobial incorporated in the edible coating needs to be effective against the target microorganisms present in the foodstuff. The incorporation of nisin in edible films or coatings to control microbial growth on food products has been investigated $(9,10)$. Also, the refrigeration

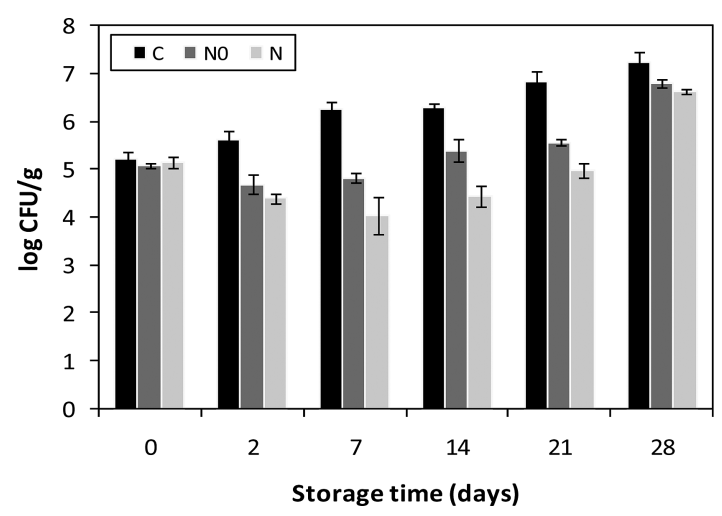

Figure 3. Listeria monocytogenes population $\left(\log \mathrm{CFU} \cdot \mathrm{g}^{-1}\right)$ on Ricotta cheese without coating $(\mathrm{C})$ and with either nisin-containing coating $(\mathrm{N})$ or no-nisin coating (NO) applied as a function of time. Error bars represent the standard deviation.

temperature is a parameter exerting a major influence on food shelf life (9); the temperature of $4{ }^{\circ} \mathrm{C}$ was chosen to perform this work.

Samples of Ricotta cheese manufactured in the laboratory had no L. monocytogenes before the application of the coating (data not shown). Figure 3 shows the effect of galactomannan coatings containing nisin on the growth of L. monocytogenes on Ricotta cheese.

Generally, L. monocytogenes cytoplasmatic membrane is damaged by low temperatures. Thus, the ability of nisin to form pores in the membrane and to destroy the cells enhances their death rate at refrigeration temperatures (30). However, the growth of L. monocytogenes in samples without coating at $4{ }^{\circ} \mathrm{C}$ was not unexpected since these bacteria are known to grow at refrigeration temperatures $(9)$.

In general, the galactomannan coating itself has shown a slight antimicrobial effect (Figure 3). $\mathrm{N}$ reduced the initial counts from 5.1 to $4.4 \log \mathrm{CFU} \cdot \mathrm{g}^{-1}$ after 2 days of storage. After 7 days, the count of L. monocytogenes in this treatment was $2.2 \mathrm{log} \mathrm{CFU} \cdot \mathrm{g}^{-1}$ lower than those in $\mathrm{C}$ samples $(p<0.05)$ and $0.7 \log \mathrm{CFU} \cdot \mathrm{g}^{-1}$ lower than those in $\mathrm{N} 0$ samples. These results showed that nisinadded coating prevented the growth of L. monocytogenes during 7 days of storage. Nisin has an amphipathic character; the Nterminal part of the molecule contains a relatively high proportion of hydrophobic residues, whereas the $\mathrm{C}$-terminal part is more hydrophilic (31). A hydrophilic surface adsorbs a higher amount of nisin than a hydrophobic one. This means that nisin activity against $L$. monocytogenes could be due to its facilitated adsorption onto the hydrophilic surface of the microorganism. SantiagoSilva et al. (32) evaluated the effect of pediocin, a bacteriocin, on the growth of L. innocua on slices of ham. They reported a $2 \log$ cycles reduction in the microbial population after 15 days at $12^{\circ} \mathrm{C}$, when cellulose films containing $50 \%$ of pediocin were applied to ham. Millette et al. (33) reported a Staphylococcus aureus reduction on sliced beef covered with palmitoylated alginate-based films containing nisin at $500 \mathrm{IU} \cdot \mathrm{mL}^{-1}$. Cheese contains a high fat level, which could favor bonds with nisin due to its hydrophobic nature. Interactions between cheese components and nisin could be further improved by electrostatic interactions (dipolar forces), once Rollema et al. (34) demonstrated that electrostatic interactions have an important role on the stabilization of nisin.

Relationship between Film Properties and Coating Performance. The increase of $P\left(\mathrm{CO}_{2}\right)$ when nisin was added to the film (Table 2) could also have a positive effect on the action of nisin against L. monocytogenes. Gandhi et al. (12) reported that the presence of $\mathrm{CO}_{2}$ enhanced the membrane permeability and the proportion of 
short-chain fatty acids in the cell membrane, which causes the pore formation by nisin.

The $\mathrm{N}$ samples collected at day 14, however, showed an increase of microbial numbers. Also, from days 21 to 28 , the microbial population recovered with a $>2 \log$ outgrowth. These results suggest that the nisin incorporated in the coating had a bacteriostatic rather than bactericidal effect. The decrease of the antimicrobial effectiveness of nisin after 14 days could possibly be due to the increase of $\mathrm{pH}$ of the cheese (Table 3). Nisin is more stable under acidic conditions, and therefore, its antimicrobial activity is enhanced at low pH (34). Ko et al. (7) demonstrated that nisin-incorporated edible films have a higher antimicrobial activity at lower $\mathrm{pH}$ values. The fact that the presence of the coating may retard $\mathrm{pH}$ increase during storage may also contribute to an improved antimicrobial activity of nisin. Nevertheless, it may be concluded that the overall effect of incorporating nisin into the galactomannan coating was to slow down the growth of L. monocytogenes on cheese stored at $4{ }^{\circ} \mathrm{C}$.

This work has shown that the combined action of nisin and galactomannan edible coatings over L. monocytogenes growth on cheese samples stored at $4{ }^{\circ} \mathrm{C}$ resulted in a reduction of the microbial count at least during 14 days of storage. These coatings may act as an additional hurdle to overcome the contamination of cheese by L. monocytogenes, thus improving the microbiological safety of Ricotta cheese during its refrigerated storage. Furthermore, edible coatings incorporating nisin not only help in retarding the growth of L. monocytogenes but also help in the maintenance of water content, therefore reducing cheese weight loss. This fact suggests an improved efficiency in water loss control, thus improving cheese quality attributes and extending its shelf life.

Further research should focus on the release kinetics of nisin into cheese when incorporated in the galactomannan films. Product development and sensory quality studies should also be performed before any of the treatments described in this work are applied to commercial products.

\section{ACKNOWLEDGMENT}

J.T.M. and M.A.C. gratefully acknowledge the Fundação para a Ciência e Tecnologia (FCT, Portugal) for their fellowships (SFRH/BD/32566/2006 and SFRH/BD/23897/2005, respectively), and B.W.S.S. acknowledges the Coordenação de Aperfeiçoamento de Pessoal de Nível Superior (CAPES, Brazil) for his fellowship. The authors thank Miguel Marques, who kindly provided the raw cow milk to make the cheese.

\section{LITERATURE CITED}

(1) Cerqueira, M. A.; Pinheiro, A. C.; Souza, B. W. S.; Lima, A. M. P.; Ribeiro, C.; Miranda, C.; Teixeira, J. A.; Moreira, R. A.; Coimbra, M. A.; Gonçalves, M. P.; Vicente, A. A. Extraction, purification and characterization of galactomannans from non-traditional sources. Carbohydr. Polym. 2009, 75, 408-414.

(2) Cerqueira, M. A.; Lima, A. M.; Souza, B. W. S.; Teixeira, J. A.; Moreira, R. A.; Vicente, A. A. Functional polysaccharides as edible coatings for cheese. J. Agric. Food Chem. 2009, 57, 14561462.

(3) Casariego, A.; Souza, B. W. S.; Vicente, A. A.; Teixeira, J. A.; Cruz, L.; Díaz, R. Chitosan coating surface properties as affected by plasticizer, surfactant and polymer concentrations in relation to the surface properties of tomato and carrot. Food Hydrocolloids 2008, 22, 1452-1459.

(4) Geraldine, R. M.; Soares, N. F. F.; Botrel, D. A.; Gonçalves, L. A. Characterization and effect of edible coatings on minimally processed garlic quality. Carbohydr. Polym. 2008, 72, 403-409.

(5) Pranoto, Y.; Rakshit, S. K.; Salokhe, V. M. Enhancing antimicrobial activity of chitosan films by incorporating garlic oil, potassium sorbate and nisin. Lebensm.-Wiss.-Technol. 2005, 38, 859-865.
(6) Kristo, E.; Koutsoumanis, K. P.; Biliaderis, C. G. Thermal, mechanical and water vapor barrier properties of sodium caseinate films containing antimicrobials and their inhibitory action on Listeria monocytogenes. Food Hydrocolloids 2008, 22, 373-386.

(7) Ko, S.; Janes, M. E.; Hettiarachchy, N. S.; Johnson, M. G. Physical and chemical properties of edible films containing nisin and their action against Listeria monocytogenes. J. Food Sci. 2001, 66, 10061011.

(8) Nguyen, V. T.; Gidley, M. J.; Dykes, G. A. Potential of a nisincontaining bacterial cellulose film to inhibit Listeria monocytogenes on processed meats. Food Microbiol. 2008, 25, 471-478.

(9) Neetoo, H.; Ye, M.; Chen, H.; Joerger, R. D.; Hicks, D. T.; Hoover, D. G. Use of nisin-coated plastic films to control Listeria monocytogenes on vacuum-packaged cold-smoked salmon. Int. J. Food Microbiol. 2008, 122, 8-15.

(10) Dawson, P. L.; Carl, G. D.; Acton, J. C.; Han, I. Y. Effect of lauric acid and nisin-impregnated soy-based films on the growth of Listeria monocytogenes on Turkey bologna. Poult. Sci. 2002, 81, 721-726.

(11) Longhi, C.; Maffeo, A.; Penta, M.; Petrone, G.; Seganti, L.; Conte, M. P. Detection of Listeria monocytogenes in Italian-style soft cheeses. J. Appl. Microbiol. 2003, 94, 879-885.

(12) Gandhi, M.; Chikindas, M. L. Listeria: A foodborne pathogen that knows how to survive. Int. J. Food Microbiol. 2007, 113 (1), 1-15.

(13) Farkye, N. Y. Acid- and Acid/Rennet-curd cheeses Part C: Acidheat coagulated cheeses. In Cheese: Chemistry, Physics and Microbiology, Major Cheese Groups, 3rd ed.; Fox, P. F., McSweeney, P. L. H., Cogan, T. M., Guinee T. P., Eds.; Elsevier Academic Press: London, U.K., 2004; Vol. 2, pp 343-348.

(14) Davies, E. A.; Bevis, H. E.; Delves-Broughton, J. The use of the bacteriocin, nisin, as a preservative in ricotta-type cheeses to control the food-borne pathogen Listeria monocytogenes. Lett. Appl. Microbiol. 1997, 24, 343-346.

(15) Samelis, J.; Kakouri, A.; Rogga, K. J.; Savvaidis, I. N.; Kontominas, M. G. Nisin treatments to control Listeria monocytogenes postprocessing contamination on Anthotyros, a traditional Greek whey cheese, stored at $4^{\circ} \mathrm{C}$ in vacuum packages. Food Microbiol. 2003, 20, 661-669.

(16) Duan, J.; Kim, K.; Daeschel, M. A.; Zhao, Y. Storability of antimicrobial chitosan-lysozyme composite coating and film-forming solutions. J. Food Sci. 2008, 73, 321-328.

(17) Cerqueira, M. A.; Lima, A. M.; Teixeira, J. A.; Moreira, R. A.; Vicente, A. Suitability of novel galactomannans as edible coatings for tropical fruits. J. Food Eng. 2009, 94, 372-378.

(18) Singh, B.; Falahee, M. B.; Adams, M. R. Synergistic inhibition of Listeria monocytogenes by nisin and garlic extract. Food Microbiol. 2001, 18, 133-139.

(19) Karbowiak, T.; Debeaufort, F.; Voilley, A. Importance of surface tension characterization for food, pharmaceutical and packaging products: a review. Crit. Rev. Food Sci. Nutr. 2006, 46, 391-407.

(20) Farris, S.; Introzzi, L.; Piergiovanni, L. Evaluation of a bio-coating as a solution to improve barrier, friction and optical properties of plastic films. Packag. Technol. Sci. 2009, 22, 69-83.

(21) Sivarooban, T.; Hettiarachchy, N. S.; Johnson, M. G. Physical and antimicrobial properties of grape seed extract, nisin, and EDTA incorporated soy protein edible films. Food Res. Int. 2008, 41, 781-785.

(22) Bifani, V.; Ramírez, C.; Ihl, M.; Rubilar, M.; García, A.; Zaritzky, N. Effects of murta (Ugni molinae Turcz) extract on gas and water vapor permeability of carboxymethylcellulose-based edible films. Lebensm.-Wiss.-Technol. 2007, 40, 1473-1481.

(23) Sebti, I.; Ham-Pichavant, F. R.; Coma, V. R. Edible bioactive fatty acid-cellulosic derivative composites used in food-packaging applications. J. Agric. Food Chem. 2002, 50, 4290-4294.

(24) Cerqueira, M. A.; Sousa-Gallagher, M. J.; Macedo, I.; RodriguezAguilera, R.; Souza, B. W. S.; Teixeira, J. A.; Vicente, A. A. Use of galactomannan edible coating application and storage temperature for prolonging shelf-life of "Regional" cheese. J. Food Eng. 2010, 97, 87-94.

(25) Morgan, F.; Bonnin, V.; Mallereau, M.-P.; Perrin, G. Survival of Listeria monocytogenes during manufacture, ripening and storage of soft lactic cheese made from raw goat milk. Int. J. Food Microbiol. 2001, 64, 217-221. 
(26) Tzoumaki, M. V.; Biliaderis, C. G.; Vasilakskis, M. Impact of edible coatings and packaging on quality of white asparagus (Asparagus officinalis, L.) during cold storage. Food Chem. 2009, 117, 55-63.

(27) Pizzillo, M.; Claps, S.; Cifuni, G. F.; Fedele, V.; Rubino, R. Effect of goat breed on the sensory, chemical and nutritional characteristics of ricotta cheese. Livest Prod Sci. 2005, 94, 33-40.

(28) Kampf, N.; Nussinovitch, A. Hydrocolloid coating of cheeses. Food Hydrocolloids 2000, 14, 531-537.

(29) Pantaleão, I.; Pintado, M. M. E.; Poças, M. F. F. Evaluation of two packaging systems for regional cheese. Food Chem. 2007, 102, 481-487.

(30) Dykes, G. A.; Withers, K. M. Sub-lethal damage of Listeria monocytogenes after long-term chilled storage at $4{ }^{\circ} \mathrm{C}$. Lett. Appl. Microbiol. 1999, 28, 45-48.

(31) Cha, D. S.; Cooksey, K.; Chinnan, M. S.; Park, H. J. Release of nisin from various heat-pressed and cast films. Lebensm.-Wiss.-Technol. 2003, 36, 209-213.
(32) Santiago-Silva, P.; Soares, N. F. F.; Nóbrega, J. E.; Júnior, M. A. W.; Barbosa, K. B. F.; Volp, A. C. P.; Zerdas, E. R. M. A.; Würlitzer, N. J. Antimicrobial efficiency of film incorporated with pediocin (ALTA $® 2351$ ) on preservation of sliced ham. Food Control 2009, 20, 85-89.

(33) Millette, M.; Le Tien, C.; Smoragiewicz, W.; Lacroix, M. Inhibition of Staphylococcus aureus on beef by nisin-containing modified alginate films and beads. Food Control 2007, 18, 878884.

(34) Rollema, H. S.; Kuipers, O. P.; Both, P.; De Vos, W. M.; Siezen, R. J. Improvement of solubility and stability of the antimicrobial peptide nisin by protein engineering. Appl. Environ. Microbiol. 1995, 61, 2873-2878.

Received for review August 8, 2009. Revised manuscript received December 21, 2009. Accepted December 21, 2009. 